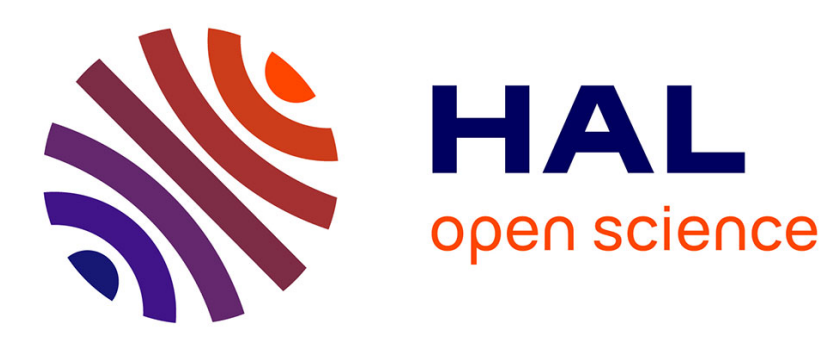

\title{
Effect of Gamma Irradiation Dose on Space Charge in e-Beam Irradiated PET Films
}

S. Mouaci, N. Saidi-Amroun, Virginie Griseri, Laurent Berquez, G. Teyssedre, N. Belkahla, M. Saidi

\section{- To cite this version:}

S. Mouaci, N. Saidi-Amroun, Virginie Griseri, Laurent Berquez, G. Teyssedre, et al.. Effect of Gamma Irradiation Dose on Space Charge in e-Beam Irradiated PET Films. 2019 IEEE Conference on Electrical Insulation and Dielectric Phenomena (CEIDP), Oct 2019, Richland, United States. pp.777-780, 10.1109/CEIDP47102.2019.9009658 . hal-03004017

\section{HAL Id: hal-03004017 https://hal.science/hal-03004017}

Submitted on 13 Nov 2020

HAL is a multi-disciplinary open access archive for the deposit and dissemination of scientific research documents, whether they are published or not. The documents may come from teaching and research institutions in France or abroad, or from public or private research centers.
L'archive ouverte pluridisciplinaire HAL, est destinée au dépôt et à la diffusion de documents scientifiques de niveau recherche, publiés ou non, émanant des établissements d'enseignement et de recherche français ou étrangers, des laboratoires publics ou privés. 


\title{
Effect of Gamma Irradiation Dose on Space Charge in e-Beam Irradiated PET Films
}

\author{
${ }^{1}$ S. Mouaci, ${ }^{1}$ N.Saidi-Amroun, ${ }^{2}$ V.Griseri, ${ }^{2}$ L. Berquez, ${ }^{2}$ G. Teyssèdre, ${ }^{1}$ N. Belkahla and ${ }^{1}$ M. Saidi \\ ${ }^{1}$ Material Physics Laboratory, Physics Faculty, University of Sciences and Technology, USTHB \\ BP 32 El-Alia, Bab-Ezzouar. Algiers, Algeria \\ ${ }^{2}$ LAPLACE, Université de Toulouse and CNRS, 118 Route de Narbonne, 31062 Toulouse Cedex 9, France
}

\begin{abstract}
Investigating radiation-induced effects in synthetic polymers makes sense for nuclear power and aerospace industries. We propose in this work to investigate the effect of the dose pre-deposited by gamma rays on the behavior of the charges implanted by electron beam in PET (polyethylene terephthalate) samples. The samples used in this study are PET films of $25 \boldsymbol{\mu m}$ in thickness. The samples were first irradiated by gamma rays, at different doses (0.1 to 2 MGy). Then, they were exposed to 20 $\mathrm{keV}$ energy electron beam, during $5 \mathrm{~min}$, with the purpose to implant electrons near the surface. Materials were characterized by different techniques, notably Light Intensity Modulation Method (LIMM) for space charge measurements and FTIR as physicochemical analysis. The results show that the electrons implanted in the PET irradiated at high dose do not stay close to the surface for a long time, which could be associated with significant material modifications at the scale of the molecules.
\end{abstract}

Keywords - Poly(ethylene terephthalate), gamma radiation, space charge, e-Beam

\section{INTRODUCTION}

The synthetic polymers have an important place in the nuclear power industry and aerospace. They are sensitive to ionizing radiation, which induces polymer chains excitation and ionization leading, eventually, to the formation of new groups called the radiation defects. The defects can be created in the chain (macromolecular defects) or emitted as small molecules (gas emission). The behavior of polymeric materials face to the irradiation remains a very delicate subject and under the study. In order to reproduce in the laboratory, at least partially, the effects of an "aggressive" environment on polymers and thus to better understand the problems that may occur, the combination of two kinds of irradiation has been studied. Indeed, at present the effects of electron beam (EB) bombardment [1, 2] or gamma rays (GR) [3, 4] on polymers have been studied separately. An important difference between the two irradiation means is that gamma irradiation produces mainly electron-hole pairs when e-beam can provide in addition primary electron deposition, breaking electrical neutrality. This can make a substantial difference when dealing with irradiation effects on the dielectric properties.

Based on the previous work on the combined effect of gamma ray and electron beam on the electrical properties of polyethylene terephthalate films [5], we present in this work the study of the behavior of the charges implanted by the electron beam on samples previously irradiated by gamma rays. Space charges in irradiated samples were probed by Light Intensity Modulation Method (LIMM) and this was complemented by Fourier Transform Infrared (FTIR) spectroscopy.

\section{EXPERIMENTAL}

\section{A. Material and irradiation}

Polyethylene-terephthalate (PET) films, $25 \mu \mathrm{m}$ thick were used in this study. The chemical structure of PET is presented in Fig. 1. The particular chemical composition of this polymer, which comprises an aromatic ring, provide it with a set of remarkable chemical, physical and dielectric properties. The samples were first subjected to ionizing radiation ( $\gamma$ rays), then bombarded with a dose of electrons.

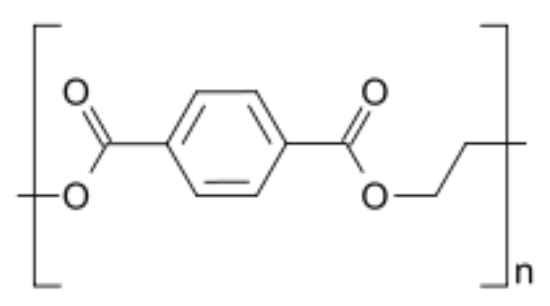

Fig. 1. The chemical structure of PET

The samples were irradiated in air, at ambient temperature, using $1.25 \mathrm{MeV}$ GR radiation source of ${ }^{60} \mathrm{Co}$ with a dose rate of $22 \mathrm{~Gy} / \mathrm{min}$. The samples were irradiated homogeneously in the dose range of 0.1 to 2 MGy using a facility available at the Nuclear Research Center of Algiers, Algeria.

EB with $20 \mathrm{keV}$ energy at a flux of a $1 \mathrm{nA} / \mathrm{cm}^{2}$ was used as post irradiation means to deposit charges. The irradiation time was 5 min. It was realized under secondary vacuum using the Matspace facility [4]. It can be considered to be homogeneous over sample surface of several $\mathrm{cm}^{2}$. With this energy, electrons are deposited within a few $\mu \mathrm{m}$ from the surface. Fig. 2 shows the maximum penetration depth of electrons predicted using the ESTAR software for PET.

\section{B. Measurement methods}

For the relatively thin films probed in this work, only thermal methods like thermal pulse or Light Intensity Modulation Method (LIMM) can provide space charge data with good spatial resolution [6]. 


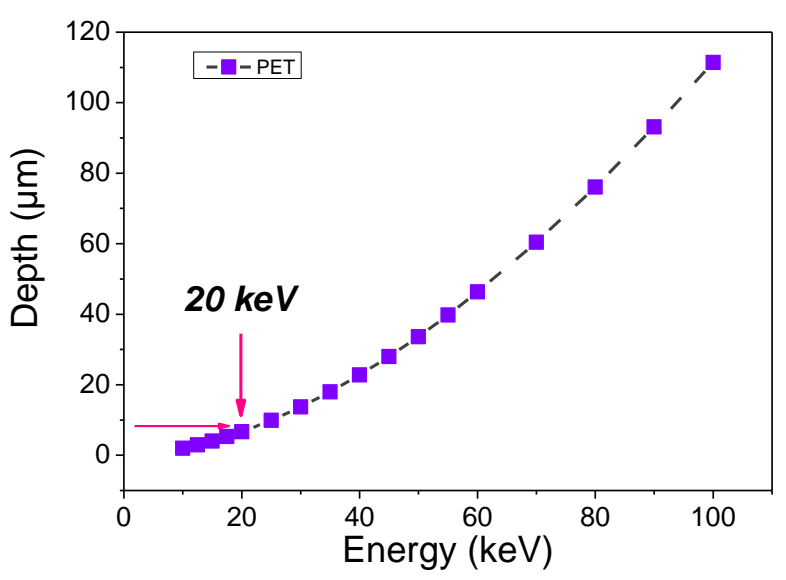

Fig. 2. Maximum electron penetration depth versus energy according to ESTAR software.

The LIMM method was selected and used in air in postirradiation conditions. It gives access to the distribution of space charge in the volume of the irradiated films, after the end of the irradiation. It is based on a perturbation of the electrostatic equilibrium consisting in a non-uniform thermal gradient created inside the material. A laser beam modulated in intensity and focused on the surface of the sample provides such thermal perturbation at frequencies in the range $10^{2}-10^{4}$ $\mathrm{Hz}$. The interaction between the thermal wave with the charge and / or the spatial polarization produces a pyroelectric current. This current is converted into a voltage and extracted from the noise by a synchronous detector that provides the real and the imaginary part of the pyroelectric current. A mathematical deconvolution then makes it possible to determine the space charge profiles [6]. The microcomputer manages the modulation frequency of the laser beam, the acquisition of the useful signal and the laser beam position on the surface of the sample.

The FTIR spectra of our polymer films were recorded in transmission mode from a Thermo-Nicolet spectrometer of a range of 400 to $4000 \mathrm{~cm}^{-1}$ with a resolution of $2 \mathrm{~cm}^{-1}$. The information extracted from the infrared absorption spectrum is qualitative and quantitative.

\section{RESULTS AND DISCUSSION}

\section{A. Physicochemical analysis}

Generally, the most obvious chemical and physical changes that occur when polymers are exposed to ionizing radiation are formation of the volatile products, the loss of mass, the appearance of unsaturated structures, the chains scission and the crosslinking [3].

The overall FTIR spectra recorded for the irradiated GR + EB PET films with different GR doses are shown in Fig. 2 and compared to the reference PET. It should be noted that the baseline has been subtracted from the spectra for a better comparison. The peaks observed in the spectral region 500 $1100 \mathrm{~cm}^{-1}$ are those reported in the literature [8-10]. The $\mathrm{CH}_{2}$ rotation in trans conformation gives the $728 \mathrm{~cm}^{-1}$ band. The bands between $847-880 \mathrm{~cm}^{-1}$ are related to the group $\mathrm{C}=\mathrm{C}-\mathrm{H}$ (aromatic ring) and the phenol group $(\mathrm{OH})$. In addition, the broad bands located between 1100 and $1300 \mathrm{~cm}^{-1}$ are attributed mainly to a C-O stretch of the ester group.

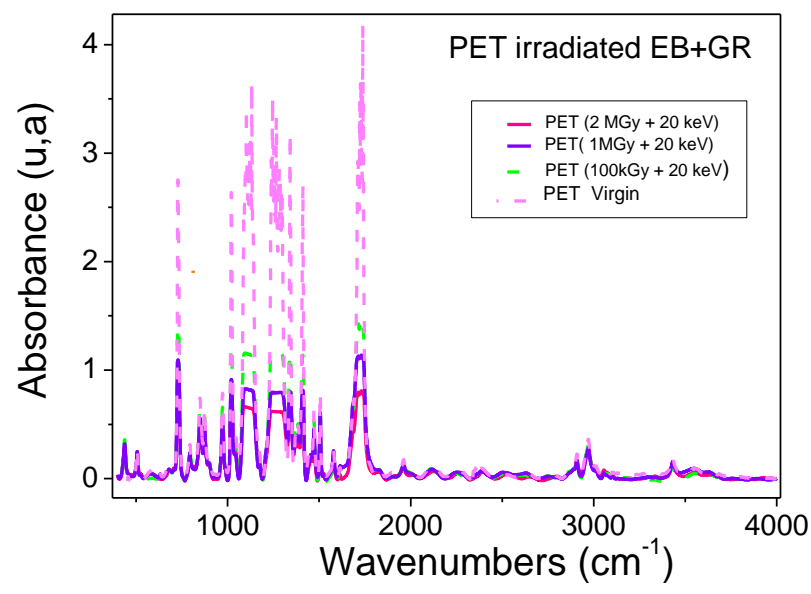

Fig.3. FTIR spectra of irradiated PET

The evolution of the area of the peaks at 728 and $1018 \mathrm{~cm}^{-1}$ as a function of the absorbed doses of GR $+\mathrm{EB}$ is shown in Fig. 3. The peaks area shows a slight rise for $100 \mathrm{kGy}$ GR dose and then it continuously decreases with a substantial for larger doses. As for the other peaks (793, 849, 873 and 972 $\mathrm{cm}^{-1}$ ), their intensities remain only slightly affected during the irradiation.

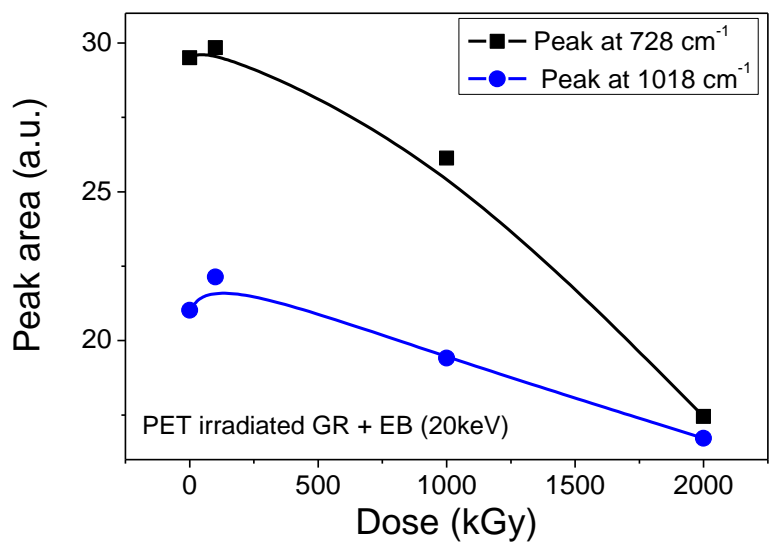

Fig. 4. The areas of the peaks at $728 \mathrm{~cm}^{-1}$ and $1018 \mathrm{~cm}^{-1}$ versus the absorbed dose.

The peaks positioned between $1471-1680 \mathrm{~cm}^{-1}$ are assigned to carboxylic acid groups. The most intense bands at $1723 \mathrm{~cm}^{-}$ ${ }^{1}$ are attributed to the $\mathrm{C}=\mathrm{O}$ carbonyl groups. To better visualize the degradation of PET after radiation exposure, we plotted the area of the peaks at 1340,1410 and $1725 \mathrm{~cm}^{-1}$ (the representation is given in Fig. 4). We find that the intensity of the peaks decreases very strongly with the absorbed dose of GR + EB. Also, the oxidation plays an important role in the degradation of the material as is has already been reported [11]. 


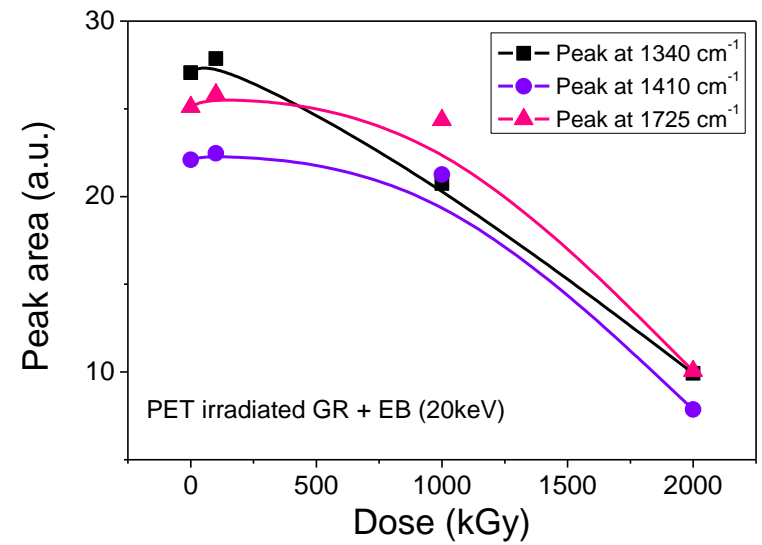

Fig. 5. The areas of the peaks at 1340,1410 and $1725 \mathrm{~cm}^{-1}$ versus the absorbed doses.

From the analysis of the FTIR spectra, we can deduce that there is a major structural evolution between the irradiated sample and virgin one, especially at high doses $(2 \mathrm{MGy}+20$ $\mathrm{keV})$. A reduction in peak intensity indicates a decrease in the concentration of the original bands and / or the change in the chemical environment of the band. This decrease is related to the degradation of the material by a scission of macromolecular chains, and consequently a decrease in the average molecular weight.

\section{B. Profiles of charges density and electric field}

The space charge measurements were performed directly after electron beam irradiation. The sample was placed in the cell, with the irradiated surface placed facing the laser beam. In such a way, the region with implanted electron is probed with improved spatial resolution. To obtain the charge density and electric field profiles, the real and imaginary parts of the pyroelectric currents are recorded then deconvolution is applied.

Fig. 6 shows the charge density profiles obtained by the LIMM method for the irradiated samples. It should be noted that the samples irradiated only with GR showed no workable signal. The charge density profiles shows the existence of two peaks, a negative charge peak near the surface and positive charge one deeper in the bulk. The positive charge detected at the very surface is probably due to artefacts in the LIMM signal conditioning [12].

The peak of negative charges is most probably due to electrons implanted by the beam. It is detected at around $2 \mu \mathrm{m}$ for the irradiated samples GR + EB. For the sample irradiated only with electrons beam, the peak is positioned at $4 \mu \mathrm{m}$. Indeed, the charges are implanted near the irradiated surface and this penetration depth is consistent with that predicted (maximum penetration $6 \mu \mathrm{m}$ ) by the model (Fig. 2).

The positive charge peak is present in the bulk for all the samples. Its origin is not clear. As PET is a polar material, one possibility is the build-up of orientation polarization under the field produced by the deposited electrons. Charge profiles with stable double peak in the bulk were observed in a similar way when homocharges were generated under high DC field and the features were observed using different techniques [13].

The detected charge amount is very large, implying very large residual fields, of the order of $100-200 \mathrm{kV} / \mathrm{mm}$, induced by space charges, see Fig.7. These very large fields produced by electron implantation may indeed drive very specific charging processes into the bulk of polar materials.

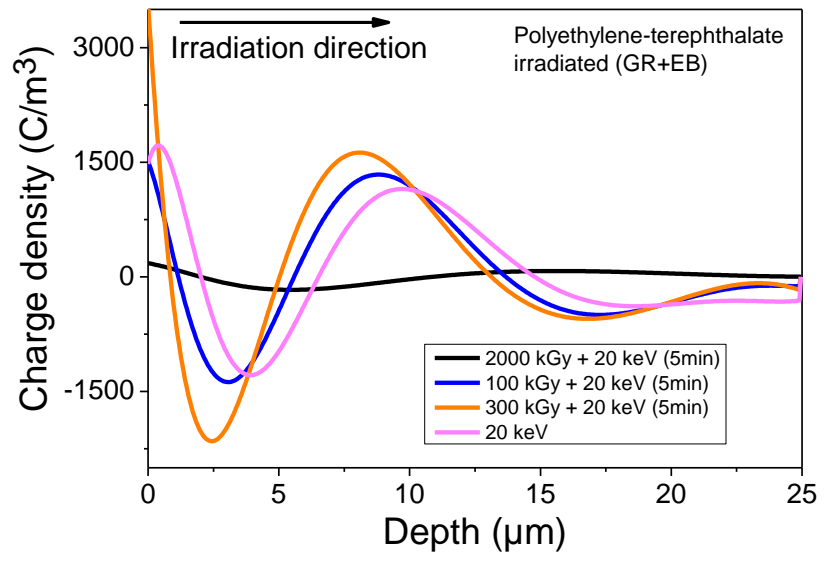

Fig. 6. Evolution of charge distribution profile as a function of the gamma doses

The internal electric field profiles of irradiated samples GR $+\mathrm{EB}$ are shown in Fig. 7. We find that the electric field is positive between 0-3 $\mu \mathrm{m}$ and negative in the region 3-10 $\mu \mathrm{m}$. Therefore, the negative charges will tend to migrate to the nonirradiated region of the sample over time. In addition, we noticed that a positive peak of field related to the positive charges is located at around $12 \mu \mathrm{m}$. This peak, observed for all moderate doses, has a larger amplitude than the one related to negative charges. This peak, observed for all moderate doses, has a larger amplitude than the one related to negative charges.

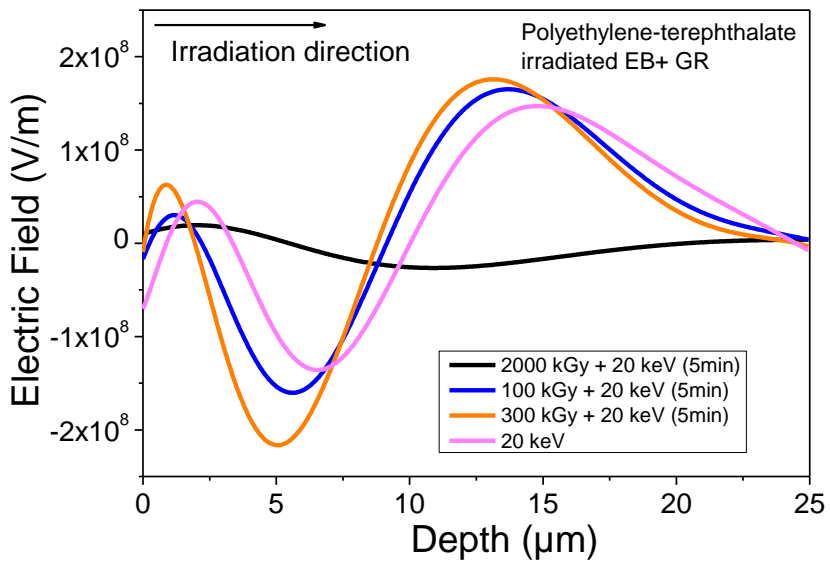

Fig. 7. Evolution of electric field distribution profile as a function of the gamma doses (Energy of electron beam : $20 \mathrm{keV}$ during $5 \mathrm{~min}$ )

An important information is the evolution of the response with the dose. For moderate GR doses, 0 to $300 \mathrm{MGy}$, the shape of the charge or field profiles does not evolve much with the dose. Also, at low dose the charge amount does not evolve 
in the same way as FTIR data. It means that main effects at the origin of charge build-up as double peak with combined irradiation sources are presumably not due to the post gamma irradiation effects (as could be the case if electron-holes pair generated would be stabilized in deep traps).

For larger GR dose (2 MGy), a much lower charge density is obtained. The signal is practically uniform and the material cannot anymore retain the charge generated by the e-beam.

In summary, the strongly irradiated sample by gamma radiation retains very little charge injected by the electrons beam (the peak of $2 \mathrm{MGy}+20 \mathrm{keV}$ is ten times less intense than that of the virgin).

\section{CONCLUSION}

In this paper we have presented the space charge distribution profiles recorded by LIMM technique and the physicochemical modification of PET samples irradiated by combined gamma-ray and electron beam sources. These results show that very high internal field can be generated into PET by e-beam irradiation and this electron implantation induced complex space charge profiles. For doses up to $300 \mathrm{kGy}$ under GR, the behavior of the samples does not depend much on the on the irradiation dose whereas FTIR spectra show noticeable evolution.

The electrons implanted in the strongly irradiated sample do not stay trapped close to the surface for a long time, which could be associated with significant modifications at the scale of the PET molecules.

\section{ACKNOWLEDGMENT}

The authors are thankful to Mansouri, Mahlous, Arib and the Director of the Nuclear Research Center of Algiers for the irradiation of the samples.

\section{REFERENCES}

[1] I.V. Vasiljeva, S.V. Mjakin, A.V. Makarov, A.N. Krasovsky, A.V. Varlamov, Electron beam induced modification of poly(ethylene terephthalate) films, Applied Surface Science, 2006, 252, 8768

[2] T. X. Nguyen, S. Bouchareb, V. Griseri, L. Berquez :"Post-Electronic Irradiation Measurements by PEA and FLIMM Methods on Dielectric Films", IEEE CEIDP, 2011, pp. 812-815.

[3] M. Mariani,U. Ravasio, G. Consolati, A. Buttafava, M. Giola, and A. Faucitano, "Gamma irradiation of PolyEthyleneTerephthalate and PolyEthyleneNaphthalate", Nucl. Instrum. Methods Phys. Res. B 265. 245-250, 2007.

[4] N. Belkahla, G. Teyssedre, N. Saidi-Amroun, M. Saidi, L. Boudou and L. Berquez.'Space charge, conduction and photoluminescence measurements in gamma irradiated poly(ethylene-2,6-naphthalate)'. Radiat. Phys. Chem., Vol. 101, 2014, pp. 73-80

[5] S. Mouaci, V. Griseri, G. Teyssedre, N. Saidi-Amroun, M. Saidi.: 'The Combined Effect of Gamma and e-Beam Irradiation on the Electrical Properties of Polyethylene Terephthalate.1 st International Conference on Dielectrics. 1, 2016, pp. 561-564

[6] R.J. Fleming,. "Space charge profile measurement techniques: recent advances and future directions", IEEE Trans. Dielectr. Electr. Insul. 12, 967-978, 2015

[7] Petre, A., Pham, C.D., Marty-Dessus, D., Berquez, L., 2009.Threedimensional space charge cartographies by FLIMM in electron irradiated polymers. J.Electrost. 67, 430-434.

[8] K.C. Cole, A. Ajji and E. Pellerin, Macromolecules., Vol. 35, 2002, pp. 770

[9] T.Steckenreiter, E. Balanzat, H.Fuess and C. Trautmann, Nucl. Instrum. meth. B.,Vol. 151, 1999, pp. 161

[10] S.S. Sheiko, I.S. Vainilovitch and S.N. Magonov, Polymer. Bull., Vol. 25, 1991, pp. 499506

[11] M. Kormunda and J. Pavlik, "Characterization of oxygen and argon ion flux interaction with PET surfaces by in-situ XPS and ex-situ FTIR", Polym. Degrad. Stab.,Vol. 95, 2010, pp. 1783-1788,

[12] S. Bouchareb. Etude de matériaux irradiés sous faisceau d'électrons, thèse doctorat UPS, 2014

[13] G. Teyssedre, C. Laurent, L. Boudou, S. Le Roy, "High electric field behavior and energetic processes in Poly(ethylene naphthalate)", Proc. IEEE Int. Conf. on Electrical Materials and Power Equipment (ICEMPE 2019), Guangzhou, China, pp. 88-93, 2019 